\title{
Analysis of the Charging Characteristics of High Voltage Capacitor Chargers Considering the Transformer Stray Capacitance
}

\author{
Byungha Lee ${ }^{*}$ and Hanju Cha ${ }^{\dagger}$ \\ *Defense Advanced R\&D Institute, Agency for Defense Development, Daejeon, Korea \\ ${ }^{\dagger}$ Dept. of Electrical Engineering, Chungnam National University, Daejeon, Korea
}

\begin{abstract}
In this paper, the charging characteristics of series resonant type high voltage capacitor chargers considering the transformer stray capacitance have been studied. The principles of operation for the four operational modes and the mode changes for the four different switching frequency sections are explained and analyzed in the range of switching frequency below the resonant frequency. It is confirmed that the average charging currents derived from the above analysis results have non-linear characteristics in each of the four modes. The resonant current, resonant voltage, charging current, and charging time of this capacitor charger as variations of the switching frequency, series parallel capacitance ratio $\left(k=C_{p} / C_{s}\right)$, and output voltage are calculated. From the calculation results, the advantages and disadvantages arising from the parallel connection of this stray capacitance are described. Some methods to minimize charging time of this capacitor charger are suggested. In addition, the results of a comparative test using two transformers whose stray capacitances are different are described. A $1.8 \mathrm{~kJ} / \mathrm{s}$ prototype capacitor charger is assembled with a TI28335 DSP controller and a $40 \mathrm{~kJ}, 7 \mathrm{kV}$ capacitor. The analysis results are verified by the experiment.
\end{abstract}

Key words: Capacitor charger, Series-parallel resonant converter, Transformer stray capacitance

\section{INTRODUCTION}

In the military pulsed power system of an Electromagnetic Launcher (EML) or Electromagnetic Armor (EMA), the capacitor bank is the most commonly used energy storage equipment because of its advantages in regards to operability, cost, ease of pulse forming, expandability and maintenance [1], [2]. The pulsed power system of an EML is composed of several paralleled segments whose capability is hundreds of $\mathrm{kJ} \sim \mathrm{MJ}$. The capacitor charger which charges this capacitor bank is requisitely installed in each segment [2]-[4] where its high efficiency, high reliability, high power density, fast charging capability are simultaneously required. Although high power capacitor chargers have often been implemented through PWM topologies [5], [6], resonant topologies have been preferred to PWM topologies because

Manuscript received Nov. 7, 2012; revised Feb. 19, 2013

Recommended for publication by Associate Editor Sangshin Kwak.

${ }^{\dagger}$ Corresponding Author: hjcha@cnu.ac.kr

Tel: +82-42-821-7006, Fax: +82-42-821-8895, Chungnam Nat'l Univ.

*Defense Advanced R\&D Inst., Agency for Defense Development, Korea the resonant topologies operate advantageously under various load conditions such as shorts or open circuit [7]-[9]. Among the various resonant topologies, the series resonant type topology which has a simple circuit, constant characteristic impedance and constant resonant frequency even in a wide range of load capacitances has been adopted more often for high voltage and high power capacitor chargers [10]-[14]. In the series resonant capacitor chargers for EMLs, a high output voltage above $10 \mathrm{kV}$ is generally required. Accordingly, many turns in the secondary side of the transformer are needed, and a non-negligible stray capacitance arises from many turns in the secondary side. A capacitance which is proportional to the square of the secondary turns is connected to the series resonant capacitance in the primary side in parallel. Consequently, the ideal series resonant charging characteristic disappears and the series-parallel resonant charging characteristic appears as the output voltage increases. As a result, the charging time taken to reach a target voltage increases in comparison with the ideal series resonant type chargers. In a recent study regarding series resonant type chargers, a charging time error 


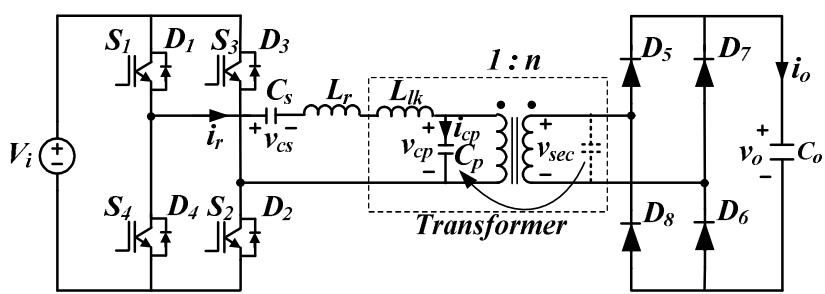

Fig. 1. Power circuit of series resonant type capacitor charger considering the transformer stray capacitance.

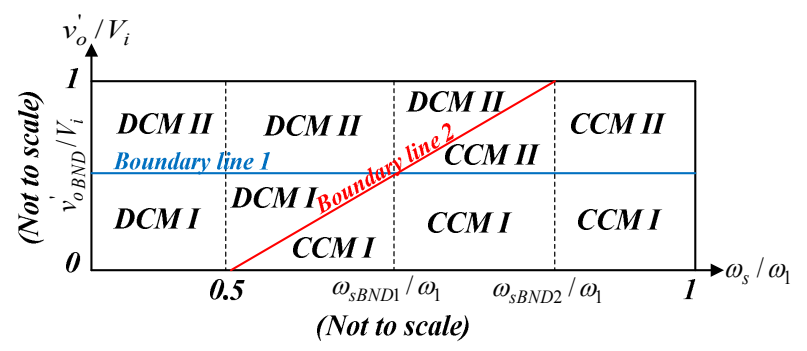

Fig. 2. Mode change by switching frequency section $\left(\omega_{s}<\omega_{1}\right)$.

was found between the design and the experiment [15]. In this paper, the charging characteristics of series resonant type high voltage capacitor chargers considering the transformer stray capacitance is studied in detail. When this charger is operated in the switching frequency range below the resonant frequency, the principles of operation include four operational modes. Discontinuous conduction mode I (DCM I), continuous conduction mode I (CCM I), discontinuous conduction mode II (DCM II), and continuous conduction mode II (CCM II) are explained and analyzed. The mode changes in terms of the four different frequency sections are explained and the average charging currents for the four operation modes are derived. According to variations of the switching frequency, series parallel capacitance ratio $\left(k=C_{p} / C_{s}\right)$ and output voltage, the charging characteristics are analyzed in terms of the normalized peak resonant current, normalized peak resonant voltage and charging time. A 1.8 $\mathrm{kJ} / \mathrm{s}$ prototype capacitor charger is constructed and analyzed. The analysis results are verified by the experiment.

\section{ANALYSIS OF High VOLTAGE CAPACITOR CHARGERS}

Fig. 1 shows a full bridge series resonant type capacitor charger with a capacitor load. Here, the parasitic resistance of the circuit is neglected. All of the switches and diodes are considered ideal. The secondary winding capacitance of the transformer, which is converted to the primary side $C_{p}$, acts as an additional resonant component. The resonant inductance $L$ is the sum of the equivalent leakage inductance of the transformer $L_{l k}$ and the inserted resonant inductance $L_{r}$. $C_{s}$ is the inserted series capacitance and $C_{o}$ is the capacitance of the high voltage output capacitor. $n$ is the turns ratio of the transformer. This capacitor charger can be operated both

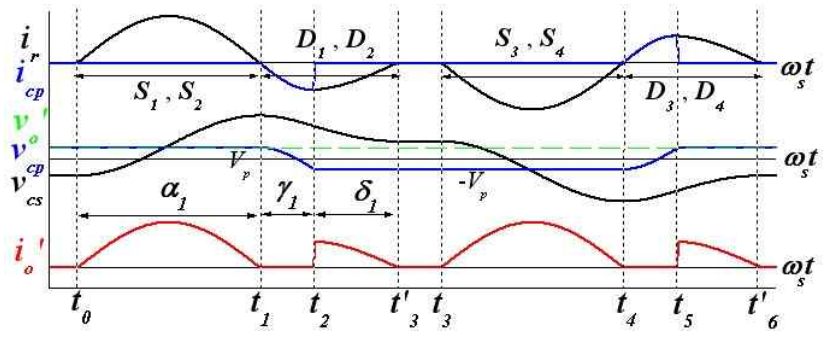

(a)

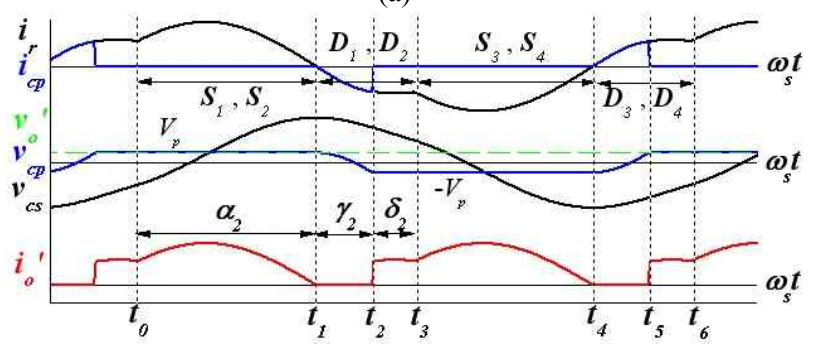

(b)

Fig. 3. Ideal waveforms of proposed capacitor charger. (a) DCM I. (b) CCM I.

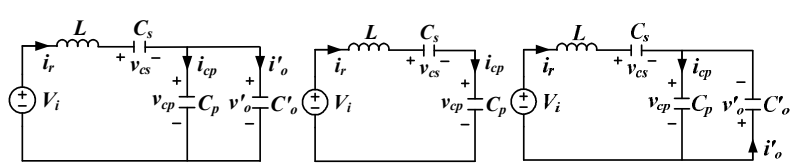

(a)

(b)

(c)

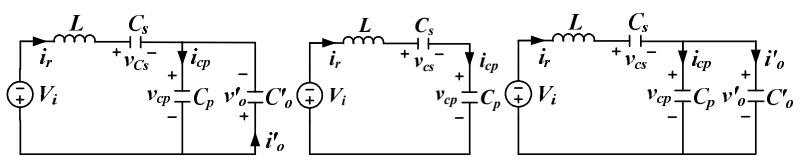

(d)

(e)

(f)

Fig. 4. Common equivalent circuit of DCM I and CCM I. (a) Mode 1. (b) Mode 2. (c) Mode 3. (d) Mode 4. (e) Mode 5. (f) Mode 6.

below and above the system resonant frequency $\omega_{1}$. However, in a high power capacitor charger, it is advantageous to operate below the resonant frequency and to use the IGBT as the main switching device because the switching loss can be minimized by zero-current turn-off. In this capacitor charger, the charging characteristic can be classified into four frequency sections, as shown in Fig. 2. The four operational modes (DCM I, CCM I, DCM II, and CCM II) are combined by each frequency section. Boundary line 1 divides the double pulse current (DPC) output mode and the single pulse current (SPC) output mode. Boundary line 2 divides the DCM and the CCM. The level of boundary line 1, the shape of boundary line 2, and the position of the boundary frequencies $\left(\omega_{S B N D 1}, \omega_{S B N D 2}\right)$ are fully changed by the $k$ value. The four operational modes (DCM I, CCM I, DCM II, and CCM II) are again divided into six operation modes (Mode $1 \sim$ Mode 6) depending on the conduction paths of $S_{1} \sim S_{4}$ and $D_{1} \sim D_{4}$. In DCM I and DCM II, there exists an additional discontinuous section where all of the switches and diodes are not conductive. 


\section{A. Principles of Operation in DCM I and CCM I}

Fig. 3 (a) and (b) show ideal waveforms in DCM I and in CCM I. Fig. 4 shows the equivalent circuits for the six operation modes which commonly appear in DCM I and CCM I.

In Mode $1\left[t_{0}-t_{1}\right], S_{1}$ and $S_{2}$ are conductive and the positive resonant current $i_{r}$ charges $C_{s}$. Meanwhile, $v_{c s}$ increases. $i_{r}$ is divided into $i_{c p}$ and $i_{o}{ }_{o}, i_{c p}$ charges $C_{p} . i_{o}^{\prime}$ charges $C^{\prime}{ }_{o}$ since $D_{5}$ and $D_{6}$ are conductive. Both $v_{c p}$ and $v^{\prime}{ }_{o}$ increase. Here, $v_{c p}$ is equal to $v_{o}^{\prime}$. Because $i_{c p}$ is much smaller than $i_{r}, v_{c p}$ has a relatively small increases in comparison with $v_{c s}$. $S_{1}$ and $S_{2}$ are naturally turned off at $t=t_{l}$ and zero current switching (ZCS) is achieved. The currents $i_{r}, i_{c p}, i_{o}$ and the voltages $v_{c s}$, $v_{c p}, v_{o}^{\prime}$ in mode 1 are derived as (1) (6) and the terms containing $i_{r}\left(t_{0}\right)$ disappear in DCM I since $i_{r}\left(t_{0}\right)=0$.

$$
i_{r}(t)=\frac{V_{i}-v_{c s}\left(t_{0}\right)-v_{c p}(t)}{Z_{1}} \sin \omega_{1}\left(t-t_{0}\right)+i_{r}\left(t_{0}\right) \cos \omega_{1}\left(t-t_{0}\right)
$$

where $Z_{1}=\sqrt{L / C_{s p o}}, \omega_{1}=1 / \sqrt{L C_{s p o}}, L=L_{r}+L_{l k}$

$$
\begin{gathered}
C_{s p o}=C_{s}\left(C_{p}+C_{o}^{\prime}\right) /\left(C_{s}+C_{p}+C_{o}^{\prime}\right), C_{p o}=C_{p}+C_{o}^{\prime}, C_{o}^{\prime}=n^{2} C_{o} \\
v_{c s}(t)=v_{c s}\left(t_{0}\right)+\frac{1}{\omega_{1} C_{s}}\left[\frac{V_{i}-v_{C s}\left(t_{0}\right)-v_{c p}\left(t_{0}\right)}{Z_{1}}\left(1-\cos \omega_{1}\left(t-t_{0}\right)\right)\right. \\
\left.+i_{r}\left(t_{0}\right) \sin \omega_{1}\left(t-t_{0}\right)\right] \\
v_{c p}(t)=v_{c p}\left(t_{0}\right)+\frac{1}{\omega_{1} C_{p o}}\left[\frac{V_{i}-v_{c s}\left(t_{0}\right)-v_{c p}\left(t_{0}\right)}{Z_{1}}\left(1-\cos \omega_{1}\left(t-t_{0}\right)\right)\right. \\
\left.+i_{r}\left(t_{0}\right) \sin \omega_{1}\left(t-t_{0}\right)\right] \\
i_{c p}(t)=\left(C_{p} / C_{p o}\right) i_{r}(t) \\
i_{o}^{\prime}(t)=\left(C_{o}^{\prime} / C_{p o}\right) i_{r}(t) \\
v_{o}^{\prime}(t)=v_{c p}(t)
\end{gathered}
$$

In Mode $2\left[t_{1}-t_{2}\right]$, the characteristic impedance of mode 1 , $Z_{1}$ is changed to $Z_{2}$. The reversed resonant current $i_{r}\left(=i_{c p}\right)$ makes $D_{1}$ and $D_{2}$ conductive. A negative $i_{r}\left(=i_{c p}\right)$ flows. $v_{c s}$ decreases and $v_{c p}$ decreases until the absolute value of $v_{c p}\left(t_{2}\right)$ is equal to $v_{c p}\left(t_{1}\right)$. Since $D_{5} \sim D_{8}$ are not conductive, $i_{o}$, does not flow, and $v^{\prime}{ }_{o}$ is constant. The terms containing $i_{r}\left(t_{l}\right)$ disappear in both DCM I and CCM I since $i_{r}\left(t_{1}\right)=0$. The currents $i_{r}, i_{c p}, i_{o}^{\prime}$ and the voltages $v_{c s}, v_{c p}, v_{o}^{\prime}$ in mode 2 are derived as $(7) \sim(12)$.

$$
i_{r}(t)=\frac{V_{i}-v_{c s}\left(t_{1}\right)-v_{c p}}{Z_{2}} \sin \omega_{2}\left(t-t_{1}\right)
$$

where $Z_{2}=\sqrt{L / C_{s p}}, \omega_{2}=1 / \sqrt{L C_{s p}}, C_{s p}=C_{s} C_{p} /\left(C_{s}+C_{p}\right)$

$$
\begin{gathered}
v_{c s}(t)=v_{c s}\left(t_{1}\right)+\frac{1}{\omega_{2} C_{s}}\left[\frac{V_{i}-v_{c s}\left(t_{1}\right)-v_{c p}\left(t_{1}\right)}{Z_{2}}\left(1-\cos \omega_{2}\left(t-t_{1}\right)\right]\right. \\
v_{c p}(t)=v_{c p}\left(t_{1}\right)+\frac{1}{\omega_{2} C_{p}}\left[\frac{V_{i}-v_{c s}\left(t_{1}\right)-v_{c p}\left(t_{1}\right)}{Z_{2}}\left(1-\cos \omega_{2}\left(t-t_{1}\right)\right]\right. \\
i_{c p}(t)=i_{r}(t) \\
i_{o}^{\prime}(t)=0 \\
v_{o}^{\prime}(t)=v_{c p}\left(t_{1}\right)
\end{gathered}
$$

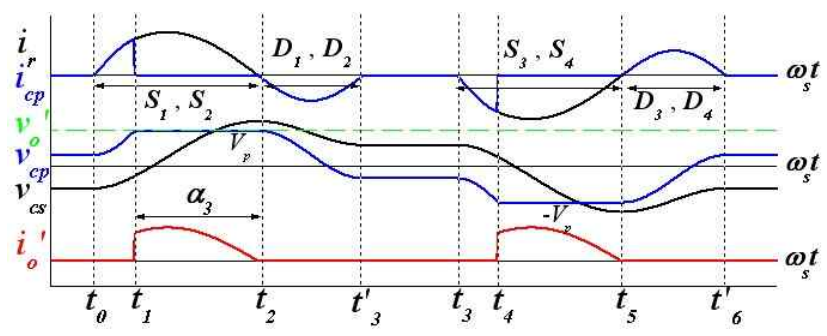

(a)

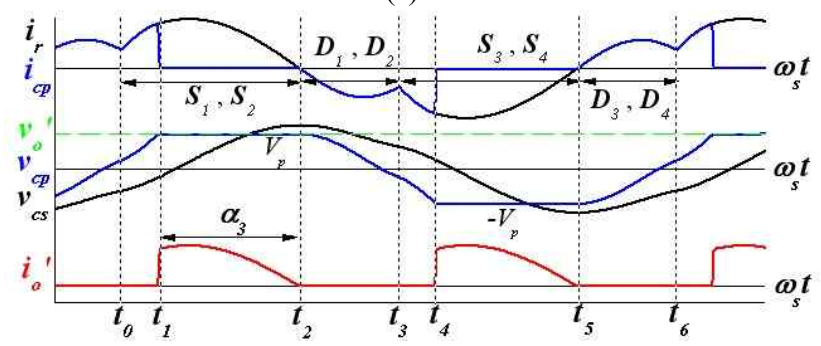

(b)

Fig. 5. Ideal waveforms of proposed capacitor charger. (a) DCM II. (b) CCM II.

In Mode $3\left[t_{2}-t_{3}\right]$, the value of $\left|v_{C p}\left(t_{2}\right)\right|$ is equal to $v_{c p}\left(t_{1}\right)$ at $t=t_{2} . D_{7}$ and $D_{8}$ are conductive. The primary side is connected to the secondary side like mode 1 . A negative $i_{r}$ is divided into a negative $i_{c p}$ and a positive $i_{o}{ }_{o} . i_{c p}$ reversely charges $C_{p}$, and $i_{o}{ }_{o}$ charges $C{ }_{o}$ again. Mode 3 in DCM I is finished when $D_{1}$ and $D_{2}$ are naturally non-conductive but mode 3 in CCM I is finished when $S_{3}$ and $S_{4}$ are forcedly conductive at $t=t_{3}$. Actually, DCM I is divided into eight operation modes and there exist two modes where all of the switches and diodes are not conductive as shown in Fig. 3 (a). The currents $i_{r}, i_{c p}$, $i_{o}{ }^{\prime}$ and the voltages $v_{c s}, v_{c p}, v_{o}^{\prime}$ in mode 3 are derived as (13) (18).

$$
\begin{gathered}
i_{r}(t)=\frac{V_{i}-v_{c s}\left(t_{2}\right)-v_{c p}\left(t_{2}\right)}{Z_{1}} \sin \omega_{1}\left(t-t_{2}\right)+i_{r}\left(t_{2}\right) \cos \omega_{1}\left(t-t_{2}\right) \\
v_{c s}(t)=v_{c s}\left(t_{2}\right)+\frac{1}{\omega_{1} C_{s}}\left[\frac{V_{i}-v_{c s}\left(t_{2}\right)-v_{c p}\left(t_{2}\right)}{Z_{1}}\left(1-\cos \omega_{1}\left(t-t_{2}\right)\right)\right. \\
\left.+i_{r}\left(t_{2}\right) \sin \omega_{1}\left(t-t_{2}\right)\right] \\
v_{c p}(t)=v_{c p}\left(t_{2}\right)+\frac{1}{\omega_{1} C_{p o}}\left[\frac{V_{i}-v_{c s}\left(t_{2}\right)-v_{c p}\left(t_{2}\right)}{Z_{1}}\left(1-\cos \omega_{1}\left(t-t_{2}\right)\right)\right. \\
\left.+i_{r}\left(t_{2}\right) \sin \omega_{1}\left(t-t_{2}\right)\right] \\
i_{c p}(t)=\left(C_{p} / C_{p o}\right) i_{r}(t) \\
i_{o}^{\prime}(t)=\left(C_{o}^{\prime} / C_{p o}\right) i_{r}(t) \\
v_{o}^{\prime}(t)=-v_{c p}(t)
\end{gathered}
$$

In the same manner, the currents and voltages for the $t_{3} \sim t_{6}$ sections can be derived using the equivalent circuit shown in Fig. 4 (d)(e)(f).

\section{B. Principles of Operation in DCM II and CCM II}

Fig. 5 (a) and (b) show ideal waveforms in DCM II and in CCM II. Fig. 6 shows the equivalent circuits for the six 


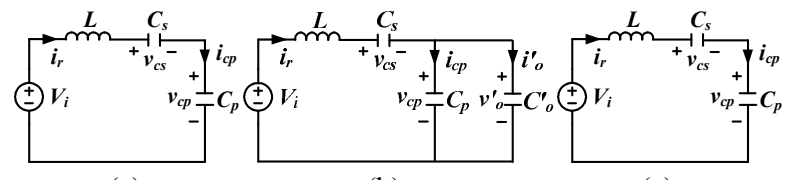

(a)

(b)

(c)

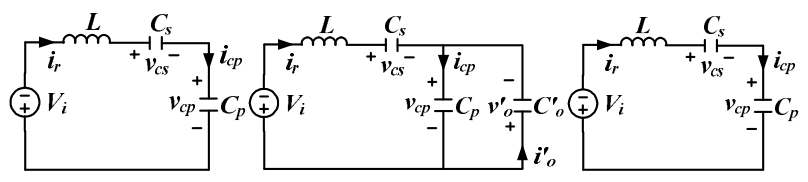

(d)

(e)

(f)

Fig. 6. Common equivalent circuit of DCM II and CCM II. (a) Mode 1. (b) Mode 2. (c) Mode 3. (d) Mode 4. (e) Mode 5. (f) Mode 6.

operation modes which commonly appear in DCM II and CCM II.

In Mode $1\left[t_{0}-t_{1}\right], S_{1}$ and $S_{2}$ are conductive, a positive resonant current $i_{r}$ charges $C_{s}$ biased reversely, and $v_{c s}$ increases. $i_{c p}\left(=i_{r}\right)$ charges $C_{p}$ and $v_{c p}$ increase until $v_{c p}$ is equal to $v_{o}{ }_{o}$ at $t=t_{2}$. Since $D_{5} \sim D_{8}$ are not conductive, $i_{o}$ does not flow, and $v^{\prime}{ }_{o}$ holds $v^{\prime}{ }_{o}\left(t_{0}\right)$. Mode 1 is finished when $v_{c p}\left(t_{l}\right)$ is equal to $v^{\prime}{ }_{o}(t)$ at $t=t_{l}$. The currents $i_{r}, i_{c p}, i_{o}{ }_{o}$ and the voltages $v_{C s}, v_{C p}, v_{o}^{\prime}$ in mode 1 are derived as (19) (24) and the terms containing $i_{r}\left(t_{0}\right)$ disappear in DCM II since $i_{r}\left(t_{0}\right)=0$.

$$
\begin{aligned}
i_{r}(t)= & \frac{V_{i}-v_{c s}\left(t_{0}\right)-v_{c p}\left(t_{0}\right)}{Z_{2}} \sin \omega_{2}\left(t-t_{0}\right)+i_{r}\left(t_{0}\right) \cos \omega_{2}\left(t-t_{0}\right) \\
v_{c s}(t)= & v_{c s}\left(t_{0}\right)+\frac{1}{\omega_{2} C_{s}}\left[\frac{V_{i}-v_{c s}\left(t_{0}\right)-v_{c p}\left(t_{0}\right)}{Z_{2}}\left(1-\cos \omega_{2}\left(t-t_{0}\right)\right)\right. \\
& \left.+i_{r}\left(t_{0}\right) \sin \omega_{2}\left(t-t_{0}\right)\right] \\
v_{c p}(t)= & v_{c p}\left(t_{0}\right)+\frac{1}{\omega_{2} C_{p}}\left[\frac{V_{i}-v_{c s}\left(t_{0}\right)-v_{c p}\left(t_{0}\right)}{Z_{2}}\left(1-\cos \omega_{2}\left(t-t_{0}\right)\right)\right. \\
& \left.+i_{r}\left(t_{0}\right) \sin \omega_{2}\left(t-t_{0}\right)\right] \quad \\
i_{c p}(t) & =i_{r}(t) \\
i_{o}^{\prime}(t) & =0 \\
v_{o}^{\prime}(t) & =v_{c p}\left(t_{1}\right)
\end{aligned}
$$

In Mode $2\left[t_{1}-t_{2}\right]$, the characteristic impedance of mode 1, $Z_{2}$ is changed to $Z_{1}$. $D_{5}$ and $D_{6}$ are conductive. The primary side is connected to the secondary side. $i_{r}$ is divided into $i_{c p}$ and $i_{o}{ }_{o}$. A positive $i_{r}$ charges $C_{s}$, and $v_{c s}$ continuously increases. A relatively small $i_{c p}$ charges $C_{p}$, and $i_{o}$ o charges $C^{\prime}{ }_{o} \cdot v_{c p}\left(=v^{\prime}{ }_{o}\right)$ increases by a very small amount. The currents $i_{r}, i_{c p}, i_{o}{ }_{o}$ and the voltages $v_{C s}, v_{C p}, v_{o}^{\prime}$ in mode 2 are derived as (25) (30).

$$
\begin{aligned}
i_{r}(t)= & \frac{V_{i}-v_{c s}\left(t_{1}\right)-v_{c p}\left(t_{1}\right)}{Z_{1}} \sin \omega_{1}\left(t-t_{1}\right)+i_{r}\left(t_{1}\right) \cos \omega_{1}\left(t-t_{1}\right) \\
v_{c s}(t)= & v_{c s}\left(t_{1}\right)+\frac{1}{\omega_{1} C_{s}}\left[\frac{V_{i}-v_{c s}\left(t_{1}\right)-v_{c p}\left(t_{1}\right)}{Z_{1}}\left(1-\cos \omega_{1}\left(t-t_{1}\right)\right)\right. \\
& \left.+i_{r}\left(t_{1}\right) \sin \omega_{1}\left(t-t_{1}\right)\right] \\
v_{c p}(t)= & v_{c p}\left(t_{1}\right)+\frac{1}{\omega_{1} C_{p o}}\left[\frac{V_{i}-v_{c s}\left(t_{1}\right)-v_{c p}\left(t_{1}\right)}{Z_{1}}\left(1-\cos \omega_{1}\left(t-t_{1}\right)\right)\right.
\end{aligned}
$$

$$
\begin{gathered}
i_{c p}(t)=\left(C_{p} / C_{p o}\right) i_{r}(t) \\
i_{o}^{\prime}(t)=\left(C_{o}^{\prime} / C_{p o}\right) i_{r}(t) \\
v_{o}^{\prime}(t)=v_{c p}(t)
\end{gathered}
$$

In Mode $3\left[t_{2}-t_{3}\right]$, the characteristic impedance of mode 2, $Z_{1}$ is again changed to $Z_{2}$. At $t=t_{2}$, the resonant current is reversed, and $D_{1}$ and $D_{2}$ are conductive. Because $v_{c p}(t)$ is less than $v_{o}^{\prime}(t), D_{5}$ and $D_{6}$ are not conductive, and the primary side is separated from the secondary side. $i_{r}\left(=i_{c p}\right)$ is circulating through $C_{p}$, and $i_{o}$, does not flow. $S_{1}$ and $S_{2}$ are naturally conductive at $t=t_{2}$ and zero current switching (ZCS) is achieved. Mode 3 in DCM II is finished when $D_{1}$ and $D_{2}$ are naturally non-conductive. However, mode 3 in CCM II is finished when $S_{3}$ and $S_{4}$ are forcedly conductive at $t=t_{3}$. The terms containing $i_{r}\left(t_{2}\right)$ disappear in both DCM II and CCM II since $i_{r}\left(t_{2}\right)=0$. The currents $i_{r}, i_{c p}, i_{o}$ and the voltages $v_{C s}, v_{C p}$, $v_{o}{ }_{o}$ in mode 3 are derived as (31) (36).

$$
\begin{gathered}
i_{r}(t)=\frac{V_{i}-v_{C s}\left(t_{2}\right)-v_{c p}\left(t_{2}\right)}{Z_{2}} \sin \omega_{2}\left(t-t_{2}\right) \\
v_{c s}(t)=v_{c s}\left(t_{2}\right)+\frac{1}{\omega_{2} C_{s}}\left[\frac{V_{i}-v_{c s}\left(t_{2}\right)-v_{c p}\left(t_{2}\right)}{Z_{2}}\left(1-\cos \omega_{2}\left(t-t_{2}\right)\right]\right. \\
v_{c p}(t)=v_{c p}\left(t_{2}\right)+\frac{1}{\omega_{2} C_{p}}\left[\frac{V_{i}-v_{C s}\left(t_{2}\right)-v_{c p}\left(t_{2}\right)}{Z_{2}}\left(1-\cos \omega_{2}\left(t-t_{2}\right)\right]\right. \\
i_{c p}(t)=i_{r}(t) \\
i_{o}^{\prime}(t)=0 \\
v_{o}^{\prime}(t)=v_{c p}\left(t_{2}\right)
\end{gathered}
$$

In the same manner, the currents and voltages for the $t_{3} \sim t_{6}$ sections can be derived using the equivalent circuit shown in Fig .6 (d)(e)(f).

\section{Mode Changes by Switching Frequency Section}

As shown in Fig. 2, when the proposed capacitor charger is operated in the range of switching frequency below the resonant frequency, the operational modes are changed differently by the four switching frequency sections as the output voltage increases.

Section I $\left[\omega_{s}<0.5 \omega_{I}\right]$ : Below boundary line 1 , this capacitor charger operates in DCM I. $\gamma_{1}=0$ at $v_{o}{ }_{o}=0$. As $v_{o}{ }_{o}$ increases, $\gamma_{I}$ also increases, and $\delta_{l}$ reduces. $\delta_{l}=0$ at $v_{o}^{\prime}=v^{\prime}{ }_{o B N D}$. Above boundary line 1 , this capacitor charger operates in DCM II. As $v^{\prime}{ }_{o}$ increases, $\alpha_{3}$ gradually decreases.

Section II $\left[0.5 \omega_{1}<\omega_{s}<\omega_{S B N D I}\right]$ : This capacitor charger initially operates in CCM I since $\omega_{s}>0.5 \omega_{1}$. As $v_{o}$ increases, $\alpha_{2}$ and $\gamma_{2}$ increase, and $\delta_{2}$ reduces. After $i_{r}=0$ at $t=t_{0}$ and $t=$ $t_{3}$ (boundary line 2), this capacitor charger operates in DCM I. The following operation is equal to section $\mathrm{I}\left[\omega_{s}<0.5 \omega_{l}\right]$. DCM I changes to DCM II at $v_{o}=v^{\prime}{ }_{O B N D}$.

Section III $\left[\omega_{s B N D 1}<\omega_{s}<\omega_{s B N D 2}\right]$ : This capacitor charger initially operates in CCM I since $\omega_{s}>0.5 \omega_{1}$ in common with section II. As $v_{o}{ }_{o}$ increases, $\alpha_{2}$ and $\gamma_{2}$ increase, and $\delta_{2}$ reduces. At $v_{o}^{\prime}=v^{\prime}{ }_{o B N D}, \delta_{2}=0$, and CCM I changes to CCM II. As $v_{o}^{\prime}$ continues to increase, CCM II changes to DCM II at 
boundary line 2 .

Section $I V\left[\omega_{S B N D 2}<\omega_{s}<\omega_{1}\right]$ : Section IV is similar to section III but DCM II does not appear in the end of charging because the value of $\omega_{s} / \omega_{1}$ is relatively large. Above boundary line $1, \alpha_{4}$ gradually decreases as $v^{\prime}{ }_{0}$ continues to increase.

\section{Nonlinearity of the Average Charging Current}

In this capacitor charger, the output capacitor is an energy storage capacitor, and the capacitance $C_{o}$ is usually at the $\mathrm{mF}$ level. As a result, the transformer stray capacitance is much smaller than the output capacitance which is converted to the primary side $\left(C_{p}<<C^{\prime}{ }_{o}\right)$ and the parallel resonant current is much smaller than series resonant current $\left(i_{c p}<<i_{r}\right)$ in mode 1 and mode 3 of DCM I and DCM II. Thus (5) and (17) can be approximated to (37). Equation (3) and (15) can also be approximated to (38).

$$
\begin{aligned}
& i_{o}^{\prime}(t)=i_{r}(t) \\
& v_{c p}(t)= \pm V_{p}
\end{aligned}
$$

Using (1) and (13), the average charging current, which is converted to the primary side during a half period $I_{o}^{\prime}$ in DCM $\mathrm{I}$, is derived as (39) and $I_{o}^{\prime}$ in CCM I is derived as (40).

$$
\begin{aligned}
& I_{o}^{\prime}=\frac{m_{s p}}{\pi}\left[\frac{V_{i}-v_{c s}\left(t_{2}\right)+V_{p}}{Z_{1}} \cos \delta_{1}-i_{r}\left(t_{2}\right) \sin \delta_{1}\right. \\
& \left.+\frac{V_{i}-2 v_{c s}\left(t_{0}\right)+v_{c s}\left(t_{2}\right)-3 V_{p}}{Z_{1}}\right] \\
& m_{s p}=\omega_{s} / \omega_{1}, \delta_{1}=\pi-\tan ^{-1}\left(\frac{i_{r}\left(t_{2}\right) Z_{1}}{V_{i}-v_{c s}\left(t_{2}\right)+V_{p}}\right) \text { or } \\
& =-\tan ^{-1}\left(\frac{i_{r}\left(t_{2}\right) Z_{1}}{V_{i}-v_{c s}\left(t_{2}\right)+V_{p}}\right)[\mathrm{rad}] \\
& I_{o}^{\prime}=\frac{m_{s p}}{\pi}\left[\frac{V_{p}+v_{c s}\left(t_{0}\right)-V_{i}}{Z_{1}} \cos \alpha_{2}+\frac{V_{i}-v_{c s}\left(t_{2}\right)+V_{p}}{Z_{1}} \cos \delta_{2}\right. \\
& \left.+i_{r}\left(t_{0}\right) \sin \alpha_{2}-i_{r}\left(t_{2}\right) \sin \delta_{2}+\frac{v_{c s}\left(t_{2}\right)-v_{c s}\left(t_{0}\right)-2 V_{p}}{Z_{1}}\right] \\
& \alpha_{2}=\pi-\tan ^{-1}\left(\frac{i_{r}\left(t_{0}\right) Z_{1}}{V_{i}-v_{c s}\left(t_{0}\right)+V_{p}}\right)[\mathrm{rad}], \\
& \text { where } \quad \gamma_{2}=\cos ^{-1}\left(1+\frac{2 V_{p}\left(1+C_{p} / C_{s}\right)}{V_{i}-V_{c s}\left(t_{1}\right)-V_{p}}\right)[\mathrm{rad}] \text {, } \\
& \delta_{2}=\pi+\sin ^{-1}\left(\frac{C}{\sqrt{A^{2}+B^{2}}}\right)-\tan ^{-1}\left(\frac{B}{A}\right) \text { or } \\
& =\sin ^{-1}\left(\frac{C}{\sqrt{A^{2}+B^{2}}}\right)-\tan ^{-1}\left(\frac{B}{A}\right), \\
& A=\frac{V_{i}-v_{c s}\left(t_{2}\right)+V_{p}}{Z_{1}}, B=\frac{V_{i}-v_{c s}\left(t_{1}\right)-V_{p}}{Z_{2}} \sin \gamma_{2}, C=\frac{V_{i}-v_{c s}\left(t_{0}\right)-V_{p}}{Z_{1}} \tan \alpha_{2} \\
& I_{o}^{\prime}=\frac{m_{s p}}{\pi}\left[\frac{V_{p}+v_{c s}\left(t_{1}\right)-V_{i}}{Z_{1}} \cos \alpha_{3}+i_{r}\left(t_{1}\right) \sin \alpha_{3}+\frac{V_{i}-v_{c s}\left(t_{1}\right)-V_{p}}{Z_{1}}\right]
\end{aligned}
$$

If the same rule $\left(C_{p}<<C^{\prime}{ }_{o}, i_{c p}<<i_{r}\right)$ is applied to mode 2 of DCM II and CCM II, (29) and (27) can each be approximated to (37) and (38). Using (25), $I_{o}^{\prime}$ in DCM II and CCM II is commonly derived as (41).
TABLE I

SPECIFICATIONS OF CAPACITOR CHARGER

\begin{tabular}{|c|r|c|r|}
\hline Parameter & \multicolumn{1}{|c|}{ Value } & Parameter & \multicolumn{1}{c|}{ Value } \\
\hline$V_{i}[\mathrm{~V}]$ & 300 & $n$ & 11 \\
\hline$V_{o}[\mathrm{~V}]$ & 3300 & $f_{s}[\mathrm{kHz}]$ & $20 \sim 32$ \\
\hline$V_{T}[\mathrm{~V}]$ & 3000 & $t_{c}[\mathrm{~s}]$ at $\omega_{s}=0.5 \omega_{1}$ & 4.6 \\
\hline$C_{o}[\mu \mathrm{F}]$ & 16.4 & $V_{B}[\mathrm{~V}]$ & 300 \\
\hline$C_{s}[\mu \mathrm{F}]$ & 0.243 & $I_{B}\left(=V_{B} / Z_{l}\right)[\mathrm{A}]$ & 18.34 \\
\hline$C_{p}[\mu \mathrm{F}]$ & $0.1 C_{s} \sim 0.5 C_{s}$ & $P_{B}\left(=V_{B} I_{B}\right)[\mathrm{W}]$ & 5502 \\
\hline$L[\mu \mathrm{H}]$ & 65 & $t_{B}[\mathrm{~s}]$ & 10 \\
\hline
\end{tabular}

where $\alpha_{3}=\pi-\tan ^{-1}\left(\frac{i_{r}\left(t_{1}\right) Z_{1}}{V_{i}-v_{c s}\left(t_{1}\right)-V_{p}}\right)$ or $=\tan ^{-1}\left(-\frac{i_{r}\left(t_{1}\right) Z_{1}}{V_{i}-v_{c s}\left(t_{1}\right)-V_{p}}\right)$

When an ideal series resonant type capacitor charger which is not considering the transformer stray capacitance is operated in DCM $\left(\omega_{s}<0.5 \omega_{r}\right), I_{o}^{\prime}$ is constant as (42), and the charging time $t_{c}$ can be easily derived using (43) [15].

$$
\begin{array}{r}
I_{o}^{\prime}=\frac{m_{s}}{\pi} \cdot \frac{4 V_{i}}{Z_{r}} \\
t_{c}=\frac{C_{o} V_{o}}{I_{o}}=\frac{n C_{o} V_{o}}{I_{o}^{\prime}}
\end{array}
$$

However, in a capacitor charger considering the transformer stray capacitance, $I_{o}^{\prime}$ is not constant in each operation mode such as (39), (40), and (41) because $i_{r}\left(t_{x}\right)$, $v_{c s}\left(t_{x}\right), \quad V_{p}, \alpha_{y}, \gamma_{y}$, and $\delta_{y}$ (where $x=0 \sim 2$ and $y=1 \sim 4$ ) are continuously changed as the output voltage increases. Thus it is very difficult to calculate an accurate charging time mathematically since $I_{o}$, appears in combination with the four switching frequency sections (section $\mathrm{I} \sim$ section IV). Because of this nonlinearity of $I_{o}^{\prime}$, several parameters including the charging time are calculated by a simulation tool (PSIM software) in this paper.

\section{SimUlation OF CHARgING CHARACTERISTICS}

Table I shows the specifications which are established for the experiment. In this capacitor charger, $C_{p o}\left(=C^{\prime}{ }_{o}+C_{p}\right)$ is connected to $C_{s}$ in series so that the equivalent capacitance $C_{s p o}$ and the system characteristic impedance $Z_{1}$ are nearly not changed even if $C_{o}$ becomes smaller than the original $C_{o}$. Thus $C_{o}$ is set to $16.4 \mu \mathrm{F}$ which is reduced by one hundredth the experimental value $1640 \mu \mathrm{F}$ to shorten the simulation time. Fig. 7 shows the currents $i_{r}, i_{c p}$, and $i_{o}$ as the output voltage increases under the conditions of $\omega_{s}=0.6 \omega_{1}$ and $k=0.1$. This capacitor charger operates in CCM I at $v^{\prime}{ }_{o} / V_{i}=0.2$. After that, it operates in DCM I at $v_{o}^{\prime} / V_{i}=0.8$ and in DCM II at $v_{o}^{\prime} / V_{i}=$ 1.0. That is, this capacitor charger has an ideal series resonant characteristic in the early stage of charging because the conduction period $\left(\gamma_{2}\right)$ of $i_{c p}$ is relatively short. However, it has a series-parallel resonant characteristic as the output voltage increases because the peak value and conduction 
period $\left(\gamma_{1}, \gamma_{2}\right)$ of $i_{c p}$ gradually increase. Fig. 8 shows the normalized peak resonant current $i_{\text {rpeak } N}\left(=i_{\text {rpeak }} / I_{B}\right)$ and voltage $v_{\text {cspeak } N}\left(=v_{\text {cspeak }} / V_{B}\right)$ as the switching frequency, output voltage, and $k$ value are changed. As the $k$ value and $v^{\prime}{ }_{o}$ increase, $i_{\text {rpeakN }}$ and $v_{\text {cspeakN }}$ totally decrease. From this effect, the rated current and voltage of the main switch, resonant component, and transformer are advantageously reduced. However, the average charging current is reduced so that the charging time $t_{c}$ to reach the target voltage $V_{T}$ disadvantageously increases. Fig. 9 shows the $v^{\prime}{ }_{o}$ curves according to the changes of the $k$ value. As the $k$ value increases, the DPC section decreases and the SPC section increases. As a result, $t_{c}$ increases. In addition, if $V_{T}$ is set up as low as possible when compared with $V_{o}, t_{c}$ decreases. For example, $t_{c}$ is smaller in $V_{T}=V_{T I}$ than it is in $V_{T}=V_{T 2}$. The smaller $C_{p}$ of the transformer (or $k$ value) is, the larger the average charging current and the larger the amount of charge which is charged to the load capacitor become. The larger the average charging current is, the smaller the charging time $t_{c}$ is. Therefore, the charging power expressed as (44) increases and the performance of the repetition rate of this capacitor charger is improved. When the $C_{p}$ value (or $k$ value) is equal to zero ultimately, the charger has an ideal series resonant charging characteristic.

$$
P_{C H}=\frac{0.5 C_{o} V_{o}}{t_{c}}
$$

Consequently, two design rules to get good performance from this series resonant capacitor charger are:

1) Design a transformer whose stray capacitance $C_{p}$ is minimized.

2) Set the target voltage $V_{T}$ as low as possible when compared with the output voltage $V_{o}$.

\section{EXPERIMENTAL RESULTS}

To verify the results of the analysis and simulation, a prototype capacitor charger $\left(1.8 \mathrm{~kJ} / \mathrm{s}\right.$ at $\left.\omega_{s} / \omega_{I}=0.5\right)$ is constructed by using the specification that are outlined in Table I, as shown in Fig.10. A $40 \mathrm{~kJ}, 7 \mathrm{kV}$, and $1640 \mu \mathrm{F}$ capacitor (ICAR) is used as the load capacitor and a $28335 \mathrm{TI}$ 32 bit floating point processor controller is used for generating the switching signal. Fig.11 show the voltage and current waveforms at $f_{s}=24 \mathrm{kHz}\left(\omega_{s} / \omega_{l}=0.6\right)$. It has been verified that CCM I, DCM I and DCM II appear sequentially as the output voltage increases through the (a), (b) and (c) waveforms. This experimental result is an example of "Section II" of "C. Mode Changes by Switching Frequency Section" in chapter II. To examine the relation between $C_{p}$ and $t_{c}$, two transformers whose $C_{p}$ values are different are tested in terms of $t_{c}$. Table II shows the parameters of two transformers (T1 and T2) which are dissimilarly designed and manufactured. Fig. 12 shows photographs, longitudinal sections, and equivalent circuits of the secondary winding of

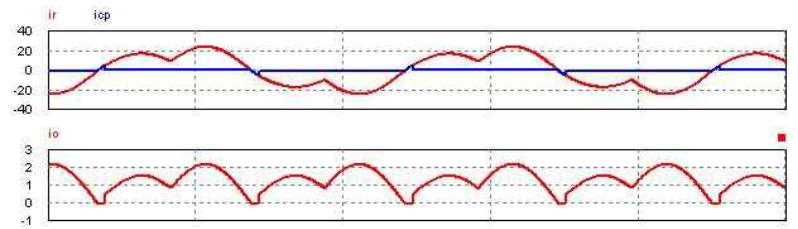

(a)

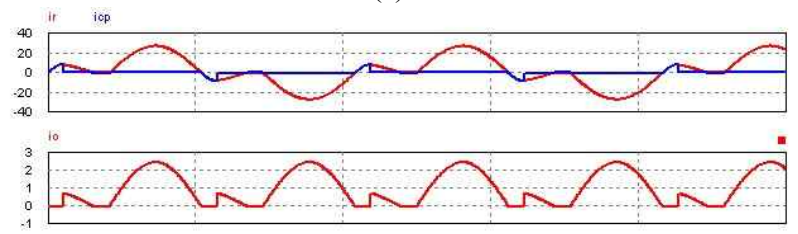

(b)

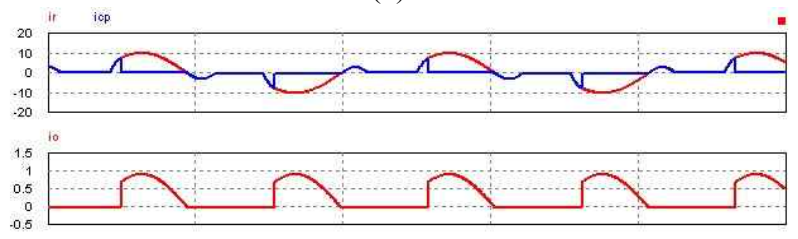

(c)

Fig. 7. $i_{r}, i_{c p}, i_{o}[x$-axis: $20 \mu \mathrm{s} / \mathrm{div}]$. (a) $v_{o^{\prime}}^{\prime} / V_{i}=0.2$. (b) $v^{\prime}{ }_{o} / V_{i}=0.8$. (c) $v_{o}^{\prime} / V_{i}=1$.

$\mathrm{T} 1$ and $\mathrm{T} 2$. The charging time $t_{c}$ increases about $18 \%$ in the experimental result by using $\mathrm{T} 1$ when compared with the simulation result using an ideal transformer. For this reason, T2 was manufactured by three different method as follows to minimize the parallel stray capacitance [16]. Firstly, the layer insulation thickness of the secondary winding was increased. As shown in Fig. 12, $D_{1}$ is the layer insulation thickness of the secondary winding of $\mathrm{T} 1$, and $\mathrm{D}_{2}$ is the layer insulation thickness of the secondary winding of $\mathrm{T} 2$. Here, $\mathrm{D}_{1}$ is smaller than $\mathrm{D}_{2}$. Secondly, the winding width of the secondary winding was decreased. $A_{1}$ is the winding width of the secondary winding of $\mathrm{T} 1$, and $\mathrm{A}_{2}$ is the winding width of the secondary winding of $\mathrm{T} 2$. Here, $\mathrm{A}_{1}$ is larger than $\mathrm{A}_{2}$. Thirdly, the layer number of the secondary winding was increased. The layer number of the secondary winding of $\mathrm{T} 1$ is 6 , and the layer number of the secondary winding of $\mathrm{T} 2$ is 7 . As the layer number increases, the series connection number of the layer to layer capacitance $\left(C_{1}\right.$ or $\left.C_{2}\right)$ increases, and the total stray capacitance $\left(C_{W}\right)$ decreases. It other words, $C_{W 2}$ is smaller than $C_{W l}$. Fig.13 shows the voltage and current waveforms during the total charging period by using $\mathrm{T} 1$ $\left(C_{p}=0.034 \mu \mathrm{F}, k=0.14\right)$ and $\mathrm{T} 2\left(C_{p}=0.023 \mu \mathrm{F}, k=0.095\right)$ at $f_{s}=20 \mathrm{kHz}$, respectively. The charging times taken to reach $V_{T}$ $=3 \mathrm{kV}$ are $5.46 \mathrm{~s}$ and $5.11 \mathrm{~s}$ which are increased by $18 \%$ and $10 \%$ in comparison with the expecting time (4.6 s) with the ideal transformer $\left(k=0, C_{p}=0\right)$. Table III and Fig.14 show the experimental and simulation results of $t_{c}$ according to variations of the $k$ value in the range of $16 \sim 26 \mathrm{kHz}$. It has been verified that a small transformer stray capacitance reduces the charging time, and improves the performance of the capacitor charger. 


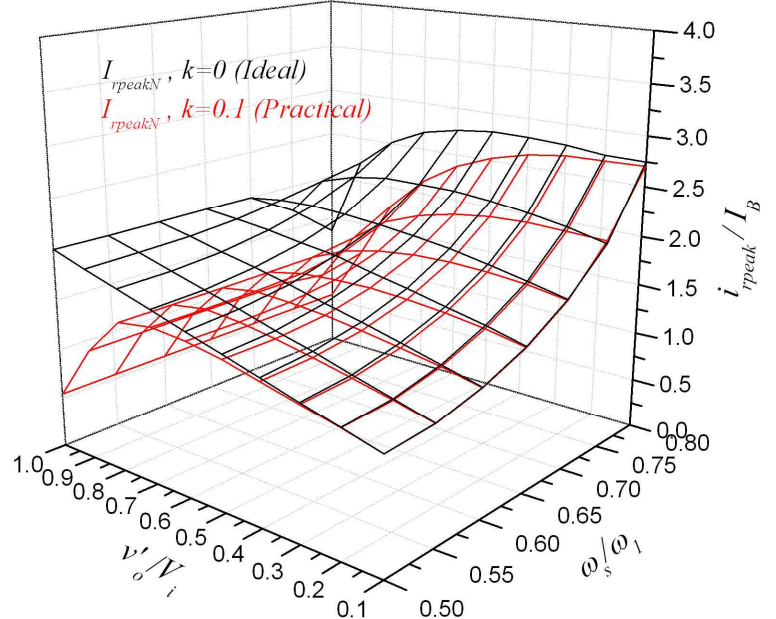

(a)

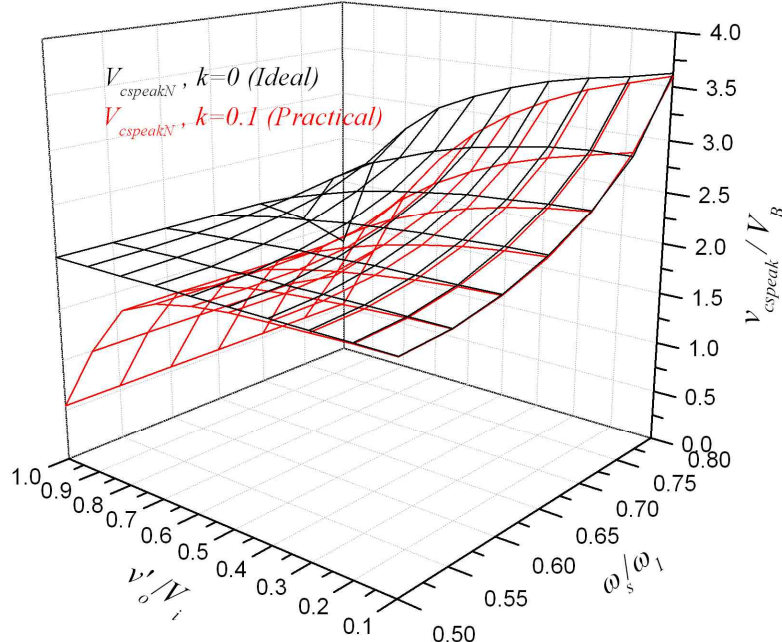

(b)

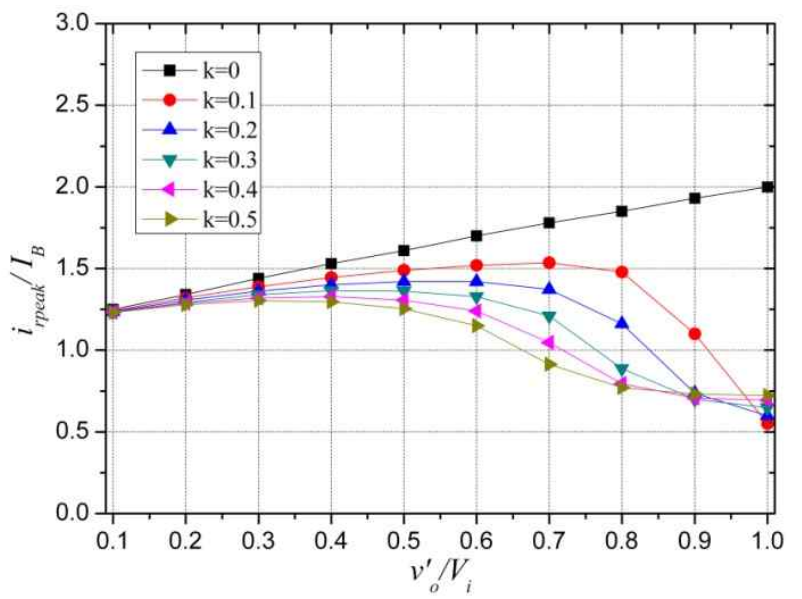

(c)

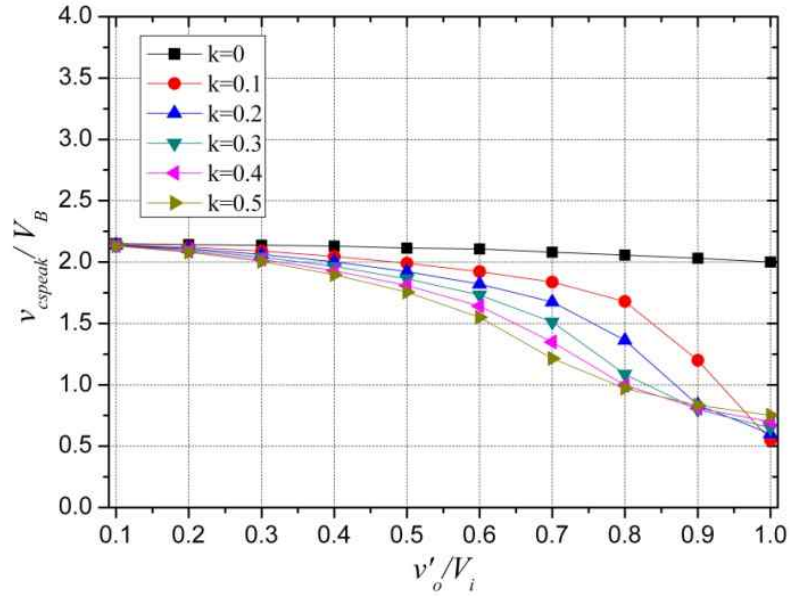

(d)

Fig. 8. Normalized current and voltage versus $k$ value variation. (a) $i_{\text {rpeak }} / I_{B}$. (b) $v_{\text {cspeak }} / V_{B}$. (c) $i_{\text {rpeak }} / I_{B}\left(\right.$ at $\left.\omega_{s} / \omega_{I}=0.6\right)$. (d) $v_{\text {cspeak }} / V_{B}$ (at $\omega_{s} / \omega_{1}=0.6$ ).

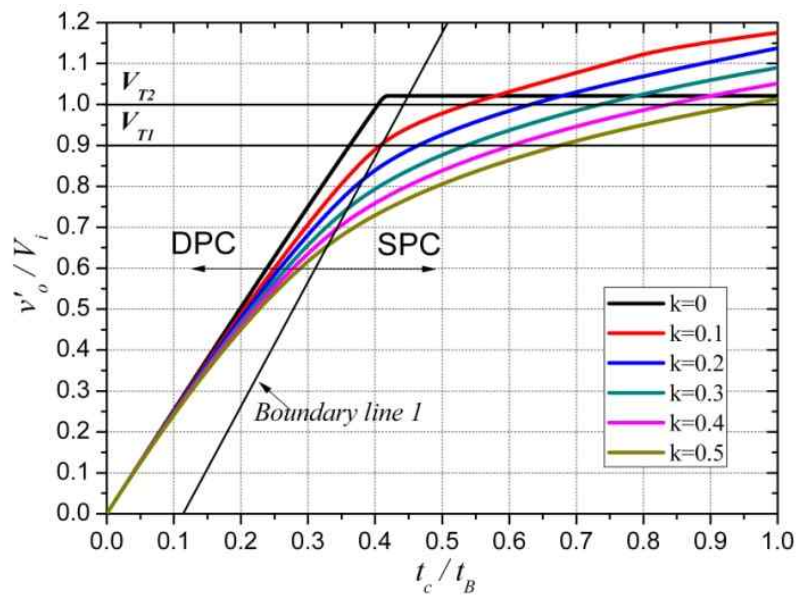

Fig. 9. $v_{o}^{\prime} / V_{i}$ and $t_{c} / t_{B}$ versus $k$ value variation at $\omega_{s} / \omega_{I}=0.6$.

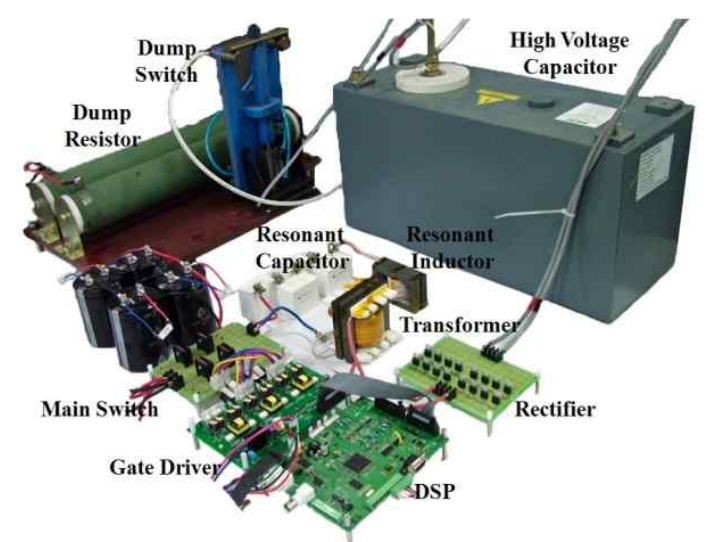

Fig. $10.1 .8 \mathrm{~kJ} / \mathrm{s}$ prototype charger with $40 \mathrm{~kJ}$ capacitor load. 


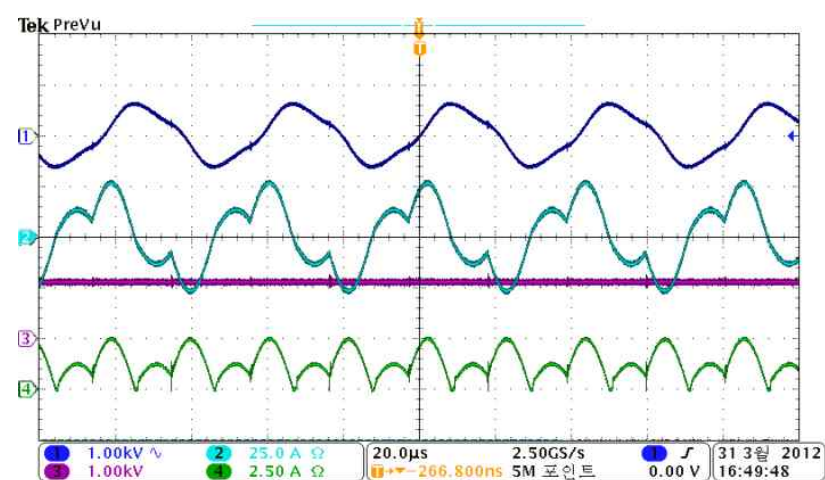

(a)

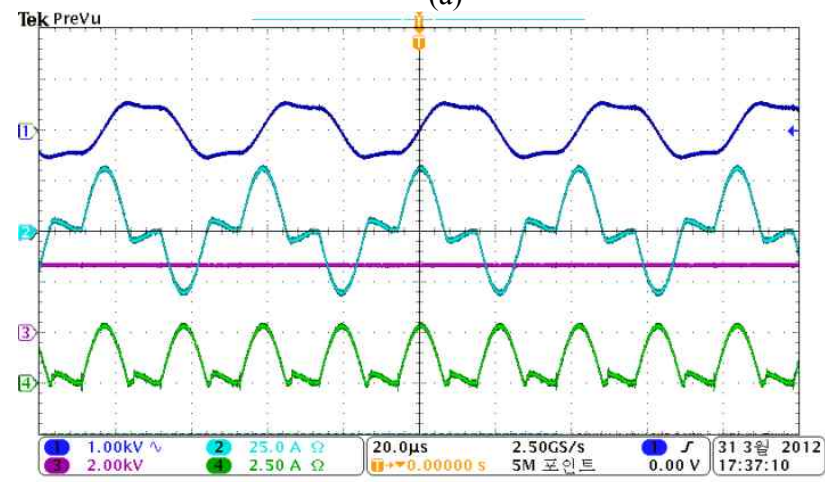

(b)

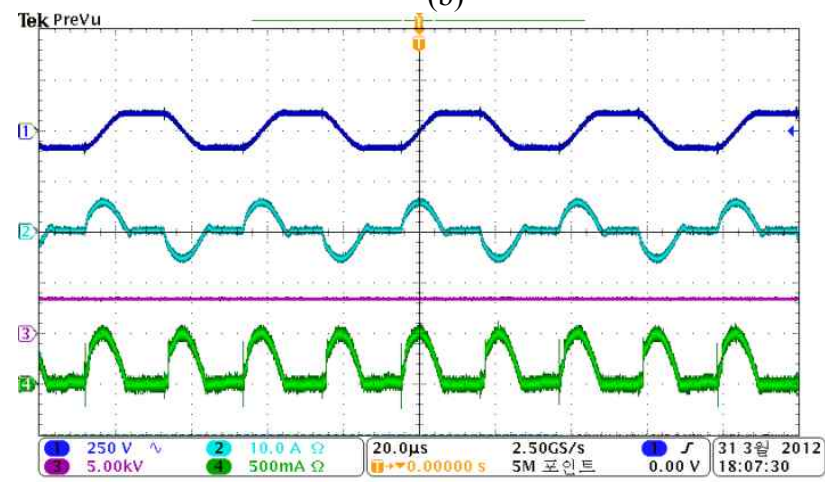

(c)

Fig. 11. Voltage and current waveforms $\left(\mathrm{CH} 1: v_{c s} \mathrm{CH} 2: i_{r} \mathrm{CH} 3: v_{o}\right.$ CH4: $i_{o}$ ). (a) $v_{o}=1.1 \mathrm{kV}$. (b) $v_{o}=2.6 \mathrm{kV}$. (c) $v_{o}=3.3 \mathrm{kV}$.

TABLE II

COMPARISON OF TWO TRANSFORMERS' PARAMETER

\begin{tabular}{|c|r|r|}
\hline Parameter & $\begin{array}{c}\text { Transformer1 } \\
\text { (T1) }\end{array}$ & $\begin{array}{c}\text { Transformer2 } \\
\text { (T2) }\end{array}$ \\
\hline Designed $B_{\max }[\mathrm{T}]$ & 0.2 & 0.25 \\
\hline $\begin{array}{c}\text { Primary : Secondary } \\
\text { [turn] }\end{array}$ & $29: 319$ & $23: 253$ \\
\hline $\begin{array}{c}\text { Primary winding } \\
\text { layer number }\end{array}$ & 2 & 7 \\
\hline $\begin{array}{c}\text { Secondary winding } \\
\text { layer number }\end{array}$ & 6 & 0.023 \\
\hline$C_{p}[\mu \mathrm{F}]$ & 0.034 & 9.17 \\
\hline$L_{l k}[\mu \mathrm{H}]$ & 14.6 & \\
\hline
\end{tabular}

TABLE III

Charging Time (Experimental Result)

\begin{tabular}{|r|r|r|r|}
\hline \multicolumn{1}{|c|}{$\boldsymbol{\omega}_{\boldsymbol{s}} / \boldsymbol{\omega}_{\boldsymbol{1}}$} & $\boldsymbol{f}_{\boldsymbol{s}}[\mathbf{k H z}]$ & $\begin{array}{c}\boldsymbol{t}_{\boldsymbol{c}}[\mathbf{s}] \\
(\mathrm{T} 1, k=0.14)\end{array}$ & $\begin{array}{c}\boldsymbol{t}_{\boldsymbol{c}}[\mathbf{s}] \\
(\mathrm{T} 2, k=0.095)\end{array}$ \\
\hline 0.4 & 16 & 6.78 & 6.36 \\
\hline 0.45 & 18 & 6.18 & 5.68 \\
\hline 0.5 & 20 & 5.46 & 5.11 \\
\hline 0.55 & 22 & 5.06 & 4.56 \\
\hline 0.6 & 24 & 4.62 & 4.11 \\
\hline 0.65 & 26 & 4.42 & 3.80 \\
\hline
\end{tabular}

(a)

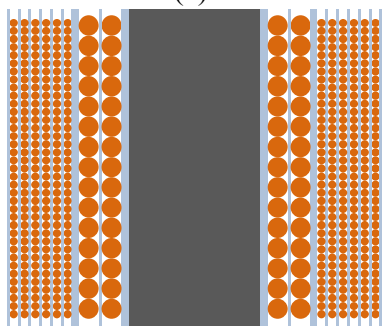

(c)

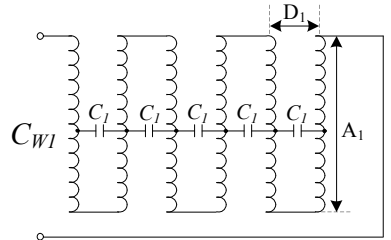

(e)

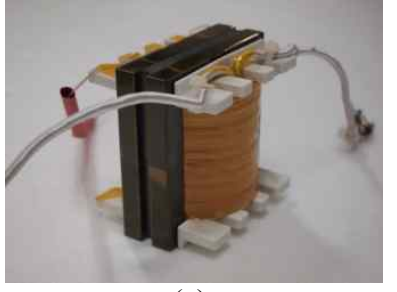

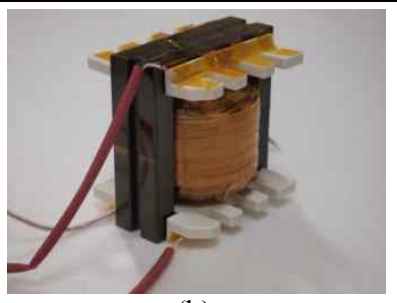

(b)

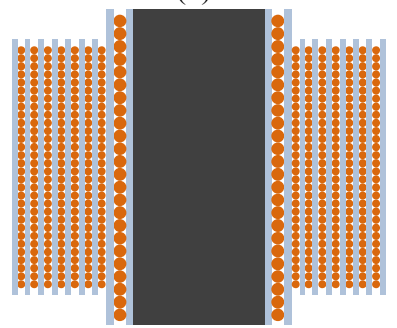

(d)

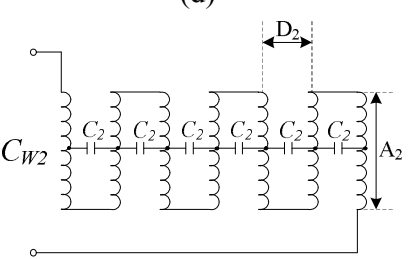

(f)
Fig.12. Comparison of the transformer1 (T1) and transformer2 (T2). (a) Photograph of T1. (b) Photograph of T2. (c) Longitudinal section of T1. (d) Longitudinal section of T2. (e) Equivalent circuit of secondary winding of T1. (f) Equivalent circuit of secondary winding of $\mathrm{T} 2$.

\section{CONCLUSIONS}

In this paper, a series resonant type high voltage capacitor charger considering the transformer stray capacitance has been studied. The operating equations of this capacitor charger have been derived and analyzed in the range of switching frequencies below the resonant frequency. Four operational modes (DCM I, CCM I, DCM II, and CCM II) are combined by the four operating frequency sections $\left(\omega_{s}<0.5 \omega_{1}, 0.5 \omega_{1}<\omega_{s}<\omega_{s B N D 1}, \omega_{s B N D 1}<\omega_{s}<\omega_{s B N D 2}\right.$, and $\omega_{s B N D 2}$ $\left.<\omega_{s}<\omega_{l}\right)$ as the output voltage increases. The following features has been confirmed in this capacitor charger. First, each average charging current for the four operational modes has a nonlinear characteristic as the output voltage increases. Second, it is possible to minimize the rated voltage and 


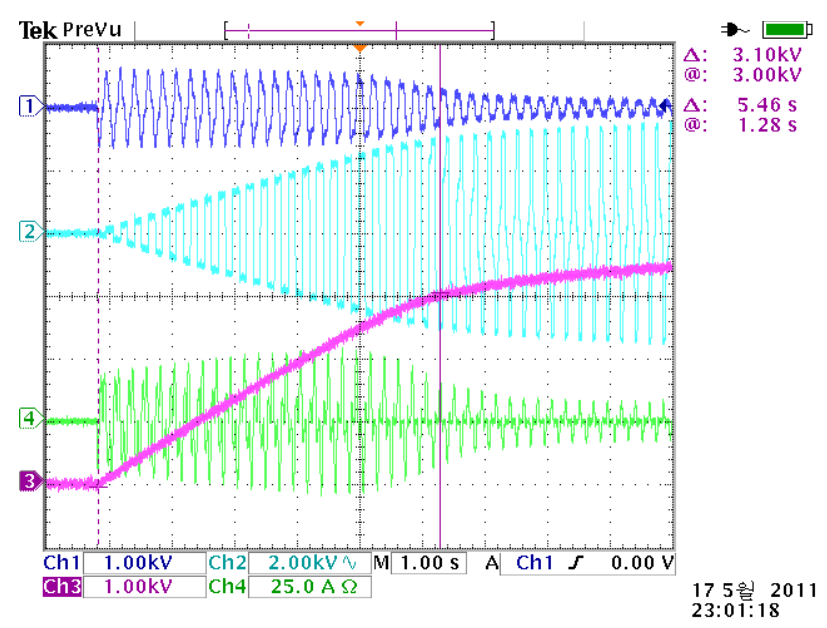

(a)

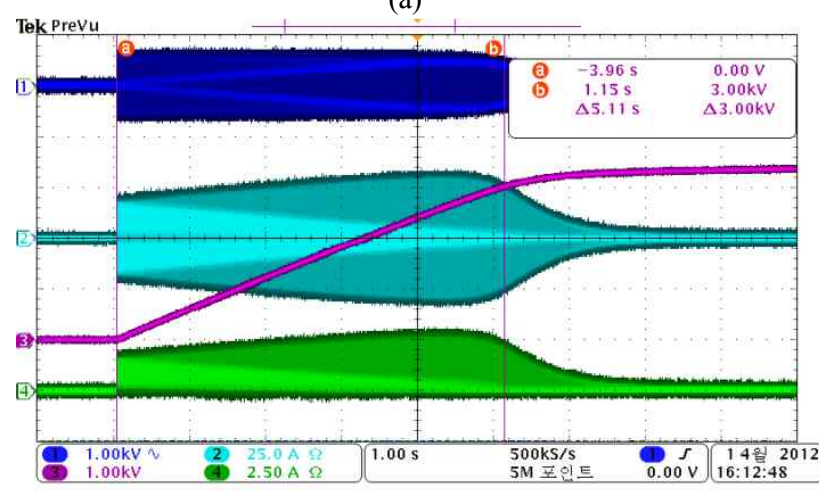

(b)

Fig. 13. Voltage and current waveforms (a) $k=0.14\left(\mathrm{CH} 1: v_{c s}\right.$ $\left.\mathrm{CH} 2: v_{s e c} \mathrm{CH} 3: v_{o} \mathrm{CH} 4: i_{r}\right)$. (b) $k=0.095\left(\mathrm{CH} 1: v_{c s} \mathrm{CH} 2: i_{r} \mathrm{CH} 3: v_{o}\right.$ $\mathrm{CH} 4: i_{o}$ ).

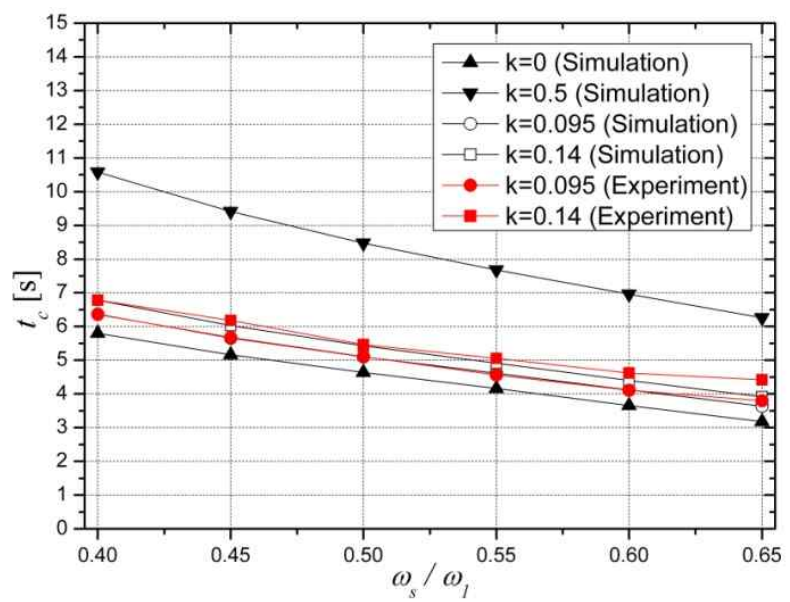

Fig. 14. Charging time ( $t_{c}$ versus $\left.\omega_{s} / \omega_{1}\right)$.

current of the main components because the resonant peak current and voltage decrease as the transformer stray capacitance increases. Third, an increase of the stray capacitance causes a decreases of the average charging current and charging time. A $1.8 \mathrm{~kJ} / \mathrm{s}$ prototype capacitor charger was constructed. The analysis and simulation results considering the transformer stray capacitance were verified by the experiment.

\section{ACKNOWLEDGMENT}

This work was supported by the Human Resources Development of the Korea Institute of Energy Technology Evaluation and Planning (KETEP) grant funded by Korea government Ministry of Knowledge Economy (No.20124030200090).

\section{REFERENCES}

[1] I. R. McNab, F. Stefani, M. Crawford, M. Eregnil, C. Persad, S. Satapathy, H. Vanicek, T. Watt, and C. Dampier, "Development of a naval railgun," IEEE Trans. Magn., Vol. 41, No. 1, pp. 206-210, Jan. 2005.

[2] M. Del Guercio, "A 4.5-MJ pulsed power supply for railgun experiments," IEEE Trans. Magn., Vol. 39, No. 1, pp. 280284, Jan. 2003

[3] T. Wolfe, P. Riedy, J. Drake, F. MacDougall, and J. Bernardes, "Preliminary design of a $200 \mathrm{MJ}$ pulsed power system for a naval railgun proof of concept facility," in Proc. 15th International Pulsed Power Conf., pp. 70-74, 2005.

[4] J. M. Neri and B. M. Human, "Operation of a 5-MJ capacitor bank for EML materials testing," in Proc. 16th International Pulsed Power Conf., pp. 1736-1739, 2007.

[5] G. Ortiz, D. Bortis, J. Biela, and J. W. Kolar, "Optimal design of a $3.5 \mathrm{kV} / 11 \mathrm{~kW}$ DC-DC converter for charging capacitor banks of power modulators," IEEE Trans. Plasma Sci., Vol. 38, No. 10, pp. 2565-2573, Oct. 2010.

[6] S.-H. Kim, B.-S. Kim, Y.-D. Lee, B.-K. Kwon, J.-S. Kim, C.-H. Choi, and S.-G. Choi, "A new capacitor charging power supply using phase-shifted PWM full-bridge converter," in Proc. IEEE-ECCE, pp. 490-494, 2009.

[7] H. Sheng, W Shen, H. Wang, D. Fu, Y. Pei, X. Yang, F. Wang, D. Boroyevich, F. C. Lee, and C. W. Tipton, "Design and implementation of a high power density three-level parallel resonant converter for capacitor charging pulsed-power supply," IEEE Trans. Plasma Sci., Vol. 39, No. 4, pp. 1131-1140, Apr. 2011.

[8] M. Borage, S. Tiwari, and S. Kotaiah, "Constant-current, constant- voltage half-bridge resonant power supply for capacitor charging," IEE Electr. Power. Appl., Vol. 153, No. 3, pp. 343-347, May 2006.

[9] Q. Tan, F. Lin, S. Wang, H. Zhong, G. Liu, and Y. Deng, "Improved capacitor charging power supply for a power conditioning system," IEEE Trans. Dielectr. Electr. Insul., Vol. 18, No. 4, pp.1214- 1220, Aug. 2011.

[10] Z. Zhang, Q. Liu, Z. Wu, Q. Wang and H. Yang, "Design and implementation of HF AC-link capacitor charging power supply," in Proc. AIMSEC, pp. 3856-3859, 2011.

[11] Y. Gao, Y. Sun, P. Yan, and Y. Shi, "High power capacitor charging power supply for EML applications," in Proc. 14th Electromagnetic Launch Technology Sympos., pp. 10-18, 2008.

[12] A. K. Jain, C. P. Henze, C. B. Henze and K. Conroy, "Development of a $350 \mathrm{~kW}, 10 \mathrm{kV}$ pulse power converter for capacitor charging," in Proc. IEEE-APEC., pp. 1164-1170, 2007. 
[13] I. W. Jung, J. S. Kim, G. I. Gusev, and G. H. Rim, "Design of $35 \mathrm{~kJ} / \mathrm{s} 25 \mathrm{kV}$ capacitor charging power supply for pulsed power system," in Proc. IEEE-IECON, pp. 2860-2863, 2004.

[14] A. C. Lippincott and R. M. Nelms, "A capacitor-charging power supply using a series-resonant topology, constant on-time/variable frequency control, and zero-current switching," IEEE Trans. Ind. Electr. Vol. 38, No. 6, pp. 438-447, Dec. 1991.

[15] B. Lee and H. Cha, "Comparative analysis of charging mode of series resonant converter for a energy storage capacitor," in Proc. IEEE-APEC, pp. 2200-2205, Feb. 2012.

[16] Colonel Wm. T. McLyman, Transformer and Inductor Design Handbook, $2^{\text {nd }}$ ed., Marcel Dekker, Inc. New York, chap. 6, 1988.

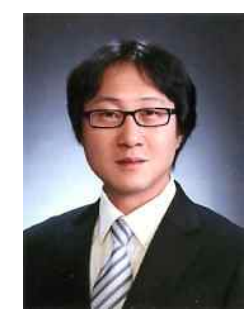

Byungha Lee received his B.S. and M.S. in Electrical Engineering from Chungnam National University, Daejeon, Korea, in 1994 and 1996, respectively, where, he is currently working toward his Ph.D. in Electrical Engineering. Since 1996, he has been a Senior Researcher with Agency for Defense Development, Daejeon, Korea. His current research interests include military pulsed-power systems and electromagnetic launch technologies.

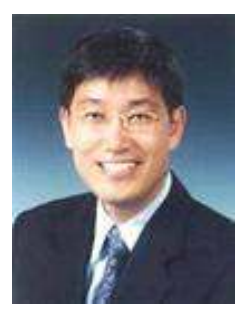

Hanju Cha received his B.S. in Electrical Engineering from Seoul National University, Seoul, Korea, in 1988, his M.S. in Electrical Engineering from the Pohang Institute of Science and Technology, Pohang, Korea, in 1990, and his Ph.D. in Electrical Engineering from Texas A\&M University, College Station, TX, USA, in 2004. From 1990 to 2001, he was with LG Industrial Systems, Anyang, Korea, where he was engaged in the development of power electronics and adjustable speed drives. Since 2005, he has been with the Department of Electrical Engineering, Chungnam National University, Daejeon, Korea. He was a Visiting Professor at the United Technology Research Center, Hartford, CT, USA, in 2009. His current research interests include high-power converters, ac/dc, dc/ac, and ac/ac converter topologies, power quality, and utility interface issues for distributed energy systems and micro-grids. 